\title{
Automation of Home using Internet of Things (IoT)
}

\author{
Mihir Narayan, Mohanty Satya Ranjan Das, Santosh Kumar Behera
}

\begin{abstract}
Home automation is popularizing more and more and becoming more and more accessible by millions of users due to its various advantages. The home automation is done by using local networking or by internet for remotely control of devices. Paper looks forward atdesigning and making home automationapplication as on the Pi through a user platform installed on various smart devices such as smart phone, smart watch, laptops etc. for selecting option for controlling operation of connected electrical devices. The results shows an efficient proposed system for smart home-automation.
\end{abstract}

\section{Keywords:relay, IoT, wifi, SoC, home automation.}

\section{INTRODUCTION}

The advancement in technology changes human life much easier bynewly advanced systems. In recent years the development in the internet sector and in embedded systems, users are now very much interested to use internet for controllingvarious electronic devices. The IoT makes a huge advancement in the technology [1][2]. Internet of Things is connecting electronicdevices like smart TVs, smart-phones, various actuators and sensors to the Internet in where devices are connectedto each other enabling the communication between multiple devices and people, and also between devices themselves. The IoT has progressed significantly in some decade because of the addition of a new technology in communication and information[3]. IoT can be used for controlling multiple devices and other objects in home automation.

Home automation is referred to applications for controlling over electrical appliances and other domestic home features. The application can have simple control over multiple lighting color to complex different types of computer/micro-controller connected networks for various degree of automation and intelligence. The homeautomation results in the convenience, energy-efficiency, and safety benefits to improved life quality[4].Therefore, the automation of the home canbe a combination of electrical and mechanical components for eliminating as much as human effort in different domestic methods and changing them with preprogrammed electrical system. This aims to increase the quality of life with the help of automation of household work that is controlled through Internet[5]. "Wireless Home security" and "Home automation" are the dual aspects of this venture. The at present assembled model of the system sends cautions to the proprietor over voice

Revised Manuscript Received on September 14, 2019.

Mihir Narayan, Dept. of Electronics \& Communication Eng.,Siksha O Anusandhan Deemed to be University, Odisha, India.(Email: mihirmohanty@soa.ac.in)

Mohanty Satya Ranjan Das, Dept. of Electronics \& Communication Eng.,Siksha O Anusandhan Deemed to be University, Odisha, India.(Email: satyadas@soa.ac.in)

Santosh Kumar Behera, Dept of Computer Sc. Engg,Siksha O Anusandhan Deemed to be University, Odisha, India.(Email santoshbehera@soa.ac.in)

calls utilizing the Internet if any kind of human involvement is detected close to the entrance of his home and raises an alert alternatively upon the user's watchfulness. The arrangement for sending ready messages to concerned security work force in the event of basic circumstance is also incorporated with the framework. Then again if the owner identifies that the individual going into his home isn't an intruder but a surprising visitor of his then as opposed to activating the security alert, the client/proprietor can make courses of action opening the entryway, turning on different machines inside the house, which are additionally associated and constrained by the micro-controller in the framework to respect his visitor. The same should be possible when the client himself goes into the room and by uprightness of the framework he can make game plans from his doorstep to such an extent that when he goes into his home he can make himself at full solace without physically exchanging on the electrical machines or his most loved T.V. channel for an example. Hence utilizing a similar arrangement of sensors the double problems of home security and home mechanization can be tackled on a complementary basis The cautions and the status of the IoT framework can be accessed by the client from anyplace even where Internet connectivity may not be promptly accessible (since it isn't fundamental for the mobile telephone to be associated with web just board is required to have an entrance to $\mathrm{Wi}-\mathrm{Fi}$ ). The existing infra-red (IR) or Blue-tooth remote controls present in the market are when all is said in done apparatus specific and the same can't be utilized conversely. Electrical appliances connected through Bluetooth utilizing Blue-tooth enabled smart telephones can't be overseen from a far off area [2].Thus capacities, for example, having the option to turn on an air-conditioner while returning home is impossible with such frameworks. In contrast, this work gives a practical and straightforward solution for remote home mechanization and home security frameworks [3][4]. The difficulty looked by current home security/surveillance systems in giving data relating to the situation to clients while being ceaselessly from home is attempted to overcome in this task.

\section{PROBLEM STATEMENT}

Main aim of this project is for supporting user to control multiple devices andelectrical appliances with a smart device that can be asmartphone, laptop, smart watch, etc. to help handicapped or elderly people who can then live without depending on any one. Proposed idea allows user with any internet enabled device to run a software on any smart device. The application allows the user to control

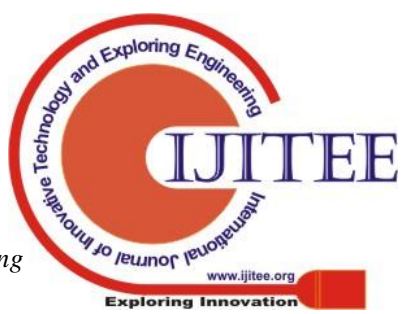


device that is connected to any home appliance.

\section{DESIGN AND IMPLEMENTATION}

Figure 1 shows integrated home automation systems along with its advantages.

There are 3 types of automation of home systems:

First Individual devices that controls only one appliance or function, examples include; programmable thermostats, motion detectors, occupancy sensors, photocell lighting controls and timers.

The distributed system connects different electrical devices to link altogether without using an external central controller.
A central system transfers signals tomainprocessor and electric appliance or betweensensors. The main leading aim of the system is to control overthe various appliances but if main controller fails, whole system will fail[5].

This paper shows microprocessor i.e. Raspberry Pi as a controller for automation of home. As a powerful computer it gave programmers and inventors and to enhance thehouses with different types of actuatorsand algorithms[10]. The practical use of the $\mathrm{Pi}$ in automationis the comparison between other sensors and development [11][12]. The analyzed resultshows that $\mathrm{Pi}$ is highly advanced computer board havingthe support forhuge number of input/output ports.

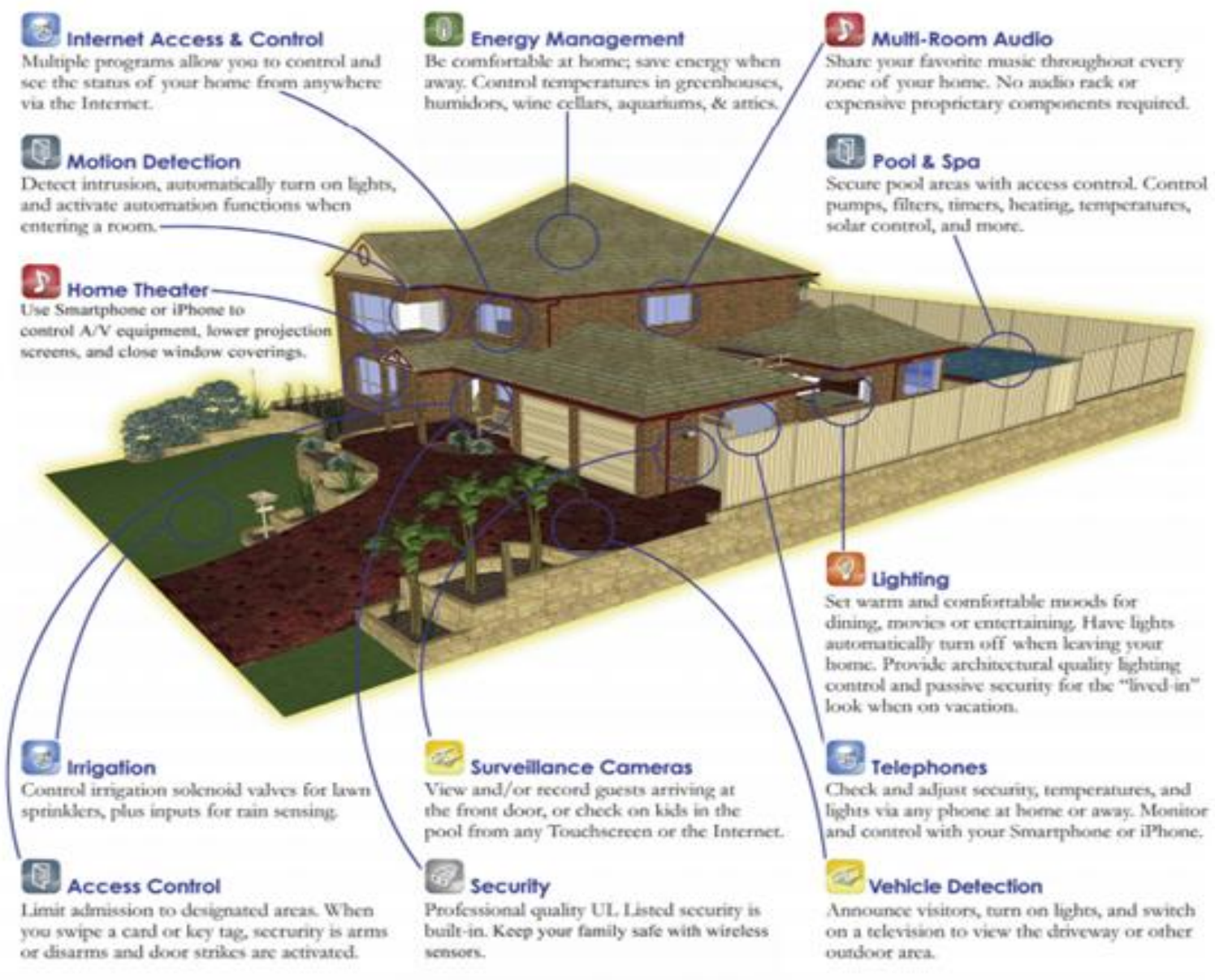

Figure 1

\section{Raspberry Pi}

Raspberry Pi (Figure 2) is a powerful computer, that weighs only around $50 \mathrm{~g}$ and affordable for around $\$ 40$. This makes it perfect for automating home, wherein small electrical appliances can be put easily in case and then can be attached in a container[10]. The Pi consists fast processor and powerfulgraphic chip, a RAM - Random-Access Memory and differentI/Oports for electrical device connection. Electrical devices and others are optional, but the Pi models consists processor [13].

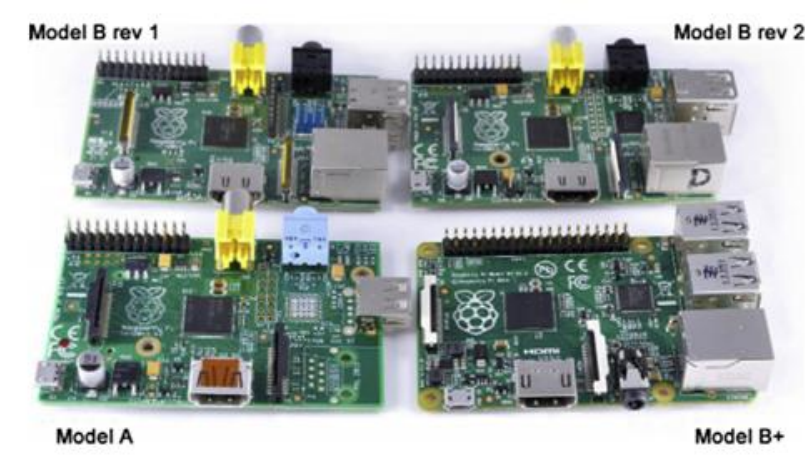

Figure 2 
Raspberry Pi, like any other computer, also uses operating system (OS) and is a part of Linux known as Raspbian.

One of the advantage of Raspberry $\mathrm{Pi}$ is that, it is very handy and flexible and can be used for various purposes. For e.g. it can be used for general computing, program learning or connectingwith electronics projects.

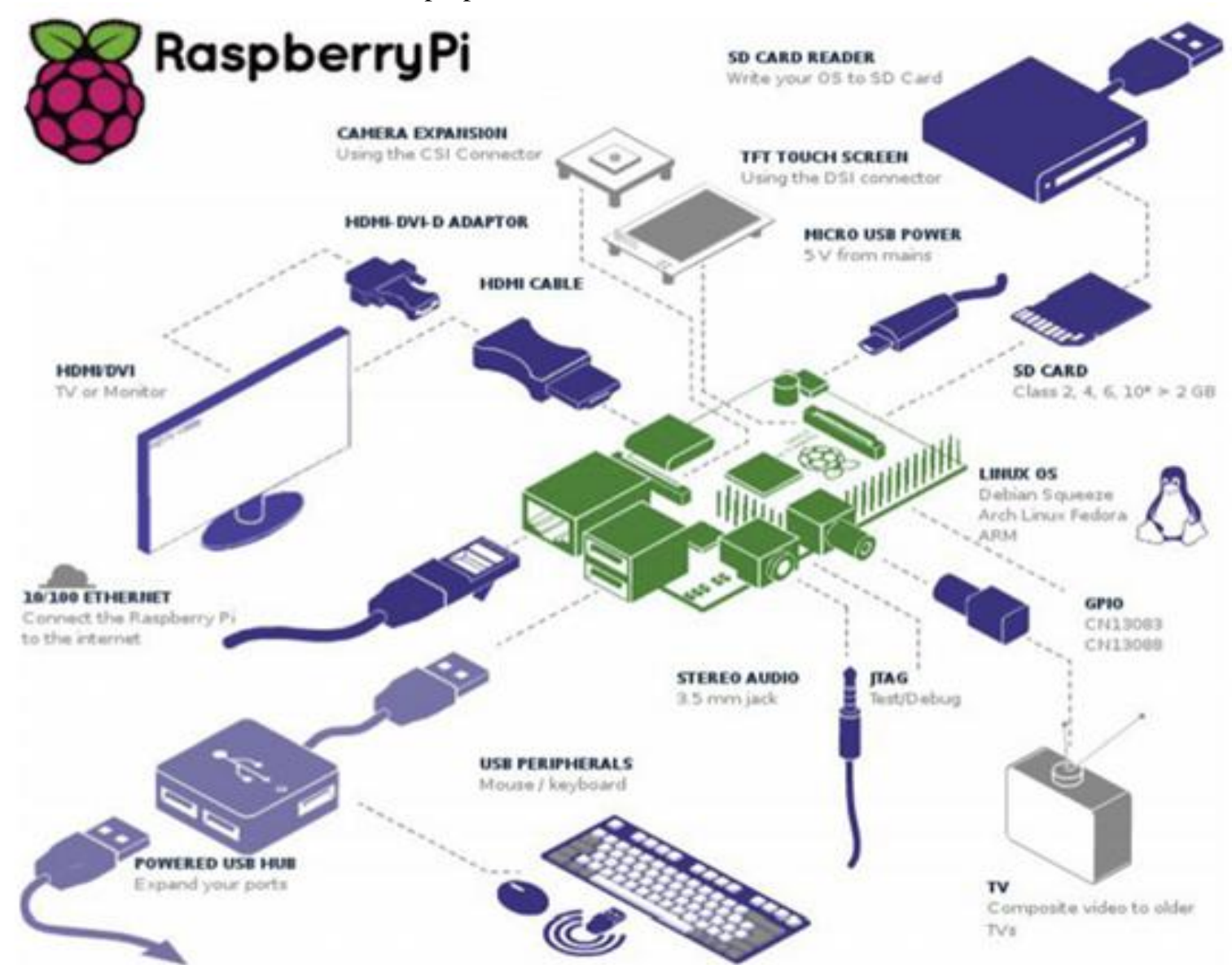

Figure 3

Relay

There are two types of relay that is used for controlling or switching high current and voltage drawing appliances, one is solid state relay and other is mechanical relay. Both relays works fine, but there is a he difference between both of them. The solid state relay uses semiconductor devices for switching appliances but mechanical relay uses electromagnets to manually switch between ON and OFF state by using metal conductor. The electro mechanical relay uses coil for actuating the switch with the help of electromagnets, this makes it cheaper. Sensors can only provide low voltages and cannot control high load appliances that where the relay comes in for controlling the appliances according to the signal received.

Very small amount of current can actuate the relay to operate and thus is perfect for this application.

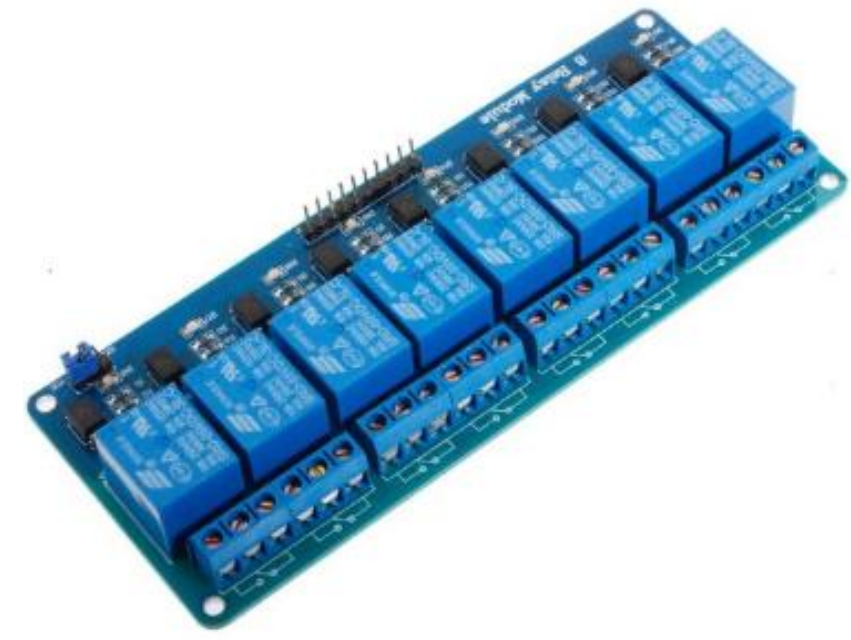

Figure 4

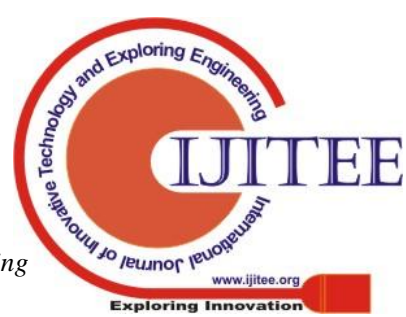




\section{SYSTEM ARCHITECTURE}

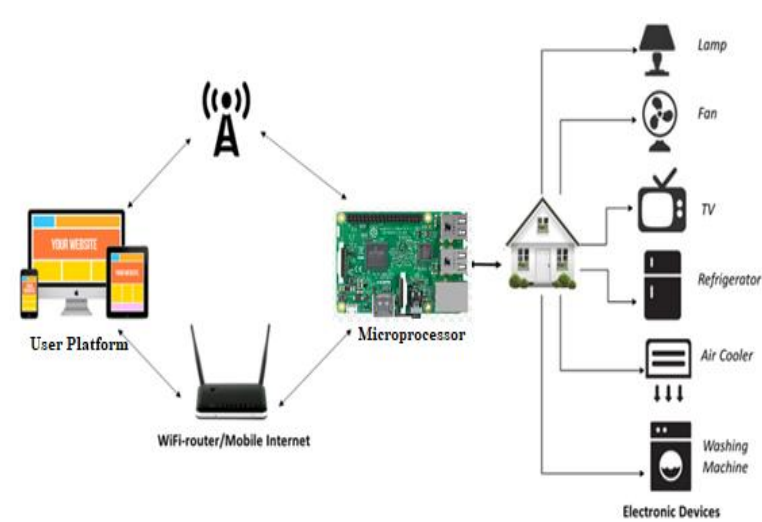

Figure 5

Figure 5 shows the block diagram of the system architecture that is used in this project. The system architecture is used to provide an architecture to the system.

\section{OPERATION OF SYSTEM \& RESULTS}

The operation of system depends upon the microprocessor i.e raspberry pi, raspberry pi is the main component of this system. The microprocessor transmits and receives signals for operating and switching multiple electronic devices at once. A user platform installed in a smart device connected to internet mainly a software or an application is used to command and control electronic devices via sending signal over the internet such as fan, light, air conditioner, television, etc. the user platform has many options for controlling multiple electronic devices, it also consists a timer for automatic shutdown and startup of a device for a pre-defined set time value, the device will automatically starts and stops according to set time.

Raspberry pi is used to receive signal over the internet via LAN or wifi module from the installed user platform in a device. The received signal then is processed and then sent to the relay module for controlling power supplied to the devices, this way relay controls connected electronic devices.

\section{CONCLUSION}

In this paper, automation of a home done by using IoT for controlling multiple electrical appliances. The aim of the paper is to control the electrical appliances connected in the homes through the smart devices. The user platform is designed in such a way that everyone can understand it and control the appliance. The system also provides device control with a timer also, for switching ON/OFF electronic devices according to preset time provided by the user. The presented system is affordable and reliable due to the use of good and low cost microprocessor and the relay.

\section{REFERENCES}

1. A. L., I. A., and M. G., "The Internet of Things: A survey," Comput. Networks, 2010.

2. S. D. T. Kelly, N. K. Suryadevara, and S. C. Mukhopadhyay, "Towards the implementation of IoT for environmental condition monitoring in homes," IEEE Sens. J., 2013.
3. P. Bhaskar, "RASPBERRY PI HOME AUTOMATION WITH WIRELESS SENSORS USING SMART PHONE,” Int. J. Comput. Sci. Mob. Comput., 2015.

4. S. Jain, A. Vaibhav, and L. Goyal, "Raspberry Pi based interactive home automation system through E-mail," in ICROIT 2014 - Proceedings of the 2014 International Conference on Reliability, Optimization and Information Technology, 2014.

5. V. Vujović and M. Maksimović, "Raspberry Pi as a Sensor Web node for home automation," Comput. Electr. Eng., 2015.

6. T. A. Abdulrahman, O. H. Isiwekpeni, N. T. SurajudeenBakinde, and A. O. Otuoze, "Design, Specification and Implementation of a Distributed Home Automation System," in Procedia Computer Science, 2016.

7. K. Mandula, R. Parupalli, C. H. A. S. Murty, E. Magesh, and R. Lunagariya, "Mobile based home automation using Internet of Things(IoT)," in 2015 International Conference on Control Instrumentation Communication and Computational Technologies, ICCICCT 2015, 2016.

8. N. David, A. Chima, A. Ugochukwu, and E. Obinna, "Design of a Home Automation System Using Arduino," Int. J. Sci. Eng. Res., 2015.

9. N. Singh, S. S. Bharti, R. Singh, and D. K. Singh, "Remotely controlled home automation system," in 2014 International Conference on Advances in Engineering and Technology Research, ICAETR 2014, 2014.

10. A. K. Dennis, Raspberry Pi Home Automation with Arduino. 2013

11. V. Vujović and M. Maksimović, "Raspberry Pi as a Wireless Sensor node: Performances and constraints," in 2014 37th International Convention on Information and Communication Technology, Electronics and Microelectronics, MIPRO 2014 - Proceedings, 2014.

12. M. Maksimović, V. Vujović, N. Davidović, V. Milošević, and B. Perišić, "Raspberry Pi as Internet of Things hardware: Performances and Constraints," in Proceedings of 1st International Conference on Electrical, Electronic and Computing Engineering IcETRAN 2014, Vrnjačka Banja, Serbia, June 2 - 5, 2014, 2014.

13. M. Schmidt, Raspberry Pi A Quick-Start Guide. 2012.

14. B. Horan, Practical Raspberry Pi. 2013. 